\title{
EFFECTS OF CURCUMIN AND NANOCURCUMIN ON CISPLATIN-INDUCED NEPHROTOXICITY IN RAT: COPPER TRANSPORTER 1 AND ORGANIC CATION TRANSPORTER 2 AS DRUG TRANSPORTERS
}

\author{
DELIANA NUR IHSANI RAHMI ${ }^{1}$, MELVA LOUISA ${ }^{2}$, VIVIAN SOETIKNO ${ }^{2 *}$ \\ ${ }^{1}$ Department of Biomedical Science Postgraduate Program, Faculty of Medicine, Universitas Indonesia, Jakarta, 10430, Indonesia. \\ ${ }^{2}$ Department of Pharmacology and Therapeutics, Faculty of Medicine, Universitas Indonesia, Jakarta, 10430, Indonesia. \\ Email: vivian_09st@yahoo.com
}

Received: 18 July 1018, Revised and Accepted: 15 November 2018

\section{ABSTRACT}

Objective: This study aimed to investigate the efficacy of curcumin (CMN) and nanocurcumin (NC) at preventing cisplatin (CDPP)-induced nephrotoxicity.

Methods: Two membrane transporters, copper transporter 1 (CTR1) and organic cation transporter 2 (OCT2), have been identified involved in active accumulation of CDPP into renal tubular cells. We analyzed OCT2 transcription levels in rat kidney tissue and determined whether renoprotective mechanism of CMN involves CTR1. Rats were randomly divided into five groups: (1) Control, (2) CDPP (7 mg/kg as single dose (i.p.), (3) CDPP+CMN $(7 \mathrm{mg} / \mathrm{kg} \mathrm{CDPP}$ as a single dose, i.p.+100 mg/kg/day of CMN), (4) CDPP+50 mg NC (7 mg/kg CDPP as single dose, i.p.+50 mg/kg/day NC), and (5) CDPP+100 mg NC (7 mg/kg CDPP as single dose, i.p.+100 mg/kg/day NC). Quantitative reverse transcription-polymerase chain reaction was performed to calculate relative expression of CTR1 and OCT2 genes in rat kidney.

Results: Expression of CTR1 was unassociated with administration of CMN or NC, indicating CTR1 is uninvolved in renoprotective mechanism of CMN. The administration of $100 \mathrm{mg} / \mathrm{kg} /$ day NC increased expression of OCT2; this increase was higher compared with normal expression levels. This may be due to another regulatory mechanism from the CMN itself.

Conclusion: NC has a better renoprotective effect compared with curcumin, suggested by the increased OCT2 expression on its administration in CDPP-treated rats.

Keywords: Cisplatin nephrotoxicity, Copper transporter 1, Curcumin, nanocurcumin, Organic cation transporter.

(C) 2018 The Authors. Published by Innovare Academic Sciences Pvt Ltd. This is an open access article under the CC BY license (http://creativecommons. org/licenses/by/4. 0/) DOI: http://dx.doi.org/10.22159/ijap.2018.v10s1.37

\section{INTRODUCTION}

Cisplatin (CDPP) (cis-diamminedichloroplatinum [II]) is a potent antineoplastic drug used for the treatment of solid tumors. It has been extensively used for a wide variety of neoplasms including those of the lung, head and neck, breast, ovary, blood, brain, kidney, and testes [1]. However, the dose of CDPP is ultimately limited due to its adverse effects, which reduces its overall effectiveness. The clinical usefulness of this drug is limited due to the presence of platinum in the kidney and liver [2]. The disproportionate accumulation of CDPP in kidney tissue contributes to CDPP-induced nephrotoxicity [3]. It clinically manifests as a lower glomerular filtration rate, higher serum creatinine, and reduced serum magnesium and potassium levels occurring in about one-third of patients undergoing CDPP treatment [4]. This adverse effect typically evolves slowly and predictably after initial and repeated exposure [5].

The major pathological basis of CDPP nephrotoxicity is renal tubular cell death on exposure [4]. CDPP is taken up by tubular cells to be eliminated from the body. In recent years, it has become evident that the cellular uptake of CDPP is mediated, at least in part, by specific transport proteins. Transport proteins that have been reported to be associated with CDPP uptake into renal tubular cells and consequent nephrotoxicity include copper transporter 1 (CTR1) and organic cation transporter 2 (OCT2) [6-8].

Curcumin (CMN) is an active compound extracted from the rhizome of the plant Curcuma longa and has been reported to have renoprotective effects [9]. CMN has been known for its numerous pharmacological activities including antioxidant, anti-inflammatory and antimicrobial properties, and chemopreventive and chemotherapeutic activity [10]. In addition, CMN appears to reverse the effects of CDPP, which includes a decrease in the expression of OCT2. This decreases in OCT2 expression in response to CDPP is believed to be a natural renoprotective mechanism of the kidney to prevent further toxicity from CDPP, the uptake of which is mediated by this transporter. Hence, a decrease in the reduction level of OCT2 in the kidneys of animals treated with CDPP and CMN indicates less renal damage compared with kidneys treated with CDPP alone. This is consistent with histopathological findings of CDPP-induced changes (particularly interstitial edema, tubular vacuolation, necrosis, and atrophy). These histopathological changes are found significantly less in CMN+CDPP-treated groups. Various studies have also demonstrated that CMN is extremely safe even at very high doses [11-16].

Unfortunately, pharmacokinetic studies of CMN have revealed poor absorption, rapid metabolism, and elimination, resulting in poor bioavailability [17]. Another factor that contributes to the poor bioavailability of CMN is its low solubility in water, and soluble CMN molecules are unstable at physiological pH [18]. Efforts have been made to enhance the bioavailability of CMN including the use of adjuvants, liposomes, micelles, phospholipid complexes, and nanoparticles [17]. In this study, nanocurcumin (NC) was used to increase the bioavailability of CMN. With enhanced bioavailability, the improved renoprotective abilities of CMN are expected to better attenuate CDPP-induced nephrotoxicity. Therefore, the aim of this study was to investigate the differences between the effects of CMN and NC in preventing CDPP-induced nephrotoxicity. To this end, we analyzed OCT2 transcription levels in rat kidney tissue and examined the effects of CMN and NC on CTR1. 


\section{METHODS}

\section{Ethics statement and experimental animals}

Male Sprague-Dawley rats weighing 150-300 g were obtained from LITBANGKES (Jakarta, Indonesia). Rats were acclimatized for a week before the study. Rats were housed under standard laboratory conditions at a temperature of $22 \pm 2^{\circ} \mathrm{C}$ with a relative humidity of $65 \pm 10 \%$ and were provided a standard pellet rodent diet and water ad libitum during the study. Experiments were approved by the Institutional Animal Ethics Committee of Universitas Indonesia.

\section{Drugs and chemicals}

Cisplatin (CDPP) was purchased from Sigma-Aldrich (St. Louis, MO, USA) and was suspended in normal saline $(0.9 \% \mathrm{NaCl})$. CMN and NC were purchased from PT Plamed Green Science Limited (China). Molecular size analysis was performed, and it was determined that the average molecular size of NC was $240.7 \mathrm{~nm}$ (standard deviation [SD]=53.5), whereas the average molecular size of $\mathrm{CMN}$ was $331.7 \mathrm{~nm}(\mathrm{SD}=91.0)$. CMN and NC were suspended in $0.5 \%$ carboxymethylcellulose (CMC).

\section{Experimental design}

A total of 23 rats were divided into five groups at random: (1) Control rats $(n=4)$, which received daily administrations of $0.5 \%$ CMC-Na orally for 9 consecutive days and a single intraperitoneal (i.p.) injection of $0.9 \%$ normal saline on the $7^{\text {th }}$ day; (2) the CDPP group ( $\left.n=4\right)$, which received daily administrations of $0.5 \%$ CMC-Na orally for 9 consecutive days and a single i.p. injection of CDPP $(7 \mathrm{mg} / \mathrm{kg}$ dissolved in $0.9 \%$ normal saline) on the $7^{\text {th }}$ day; (3) the CDPP+CMN group ( $\left.n=5\right)$, which received daily administrations of CMN $(100 \mathrm{mg} / \mathrm{kg} /$ day dispersed in $0.5 \%$ CMC-Na) orally for 9 consecutive days and a single i.p. injection of CDPP $\left(7 \mathrm{mg} / \mathrm{kg}\right.$ dissolved in $0.9 \%$ normal saline) on the $7^{\text {th }}$ day; (4) the $\mathrm{CDPP}+50 \mathrm{mg} \mathrm{NC}$ group $(\mathrm{n}=5)$, which received daily administrations of NC $(50 \mathrm{mg} / \mathrm{kg} /$ day dispersed in $0.5 \%$ CMC-Na) orally for 9 consecutive days and a single i.p. injection of CDPP (7 mg/kg dissolved in $0.9 \%$ normal saline) on the $7^{\text {th }}$ day; and (5) the CDPP $+100 \mathrm{mg} \mathrm{NC}$ group $(\mathrm{n}=5)$, which received daily administrations of $\mathrm{NC}(100 \mathrm{mg} / \mathrm{kg} /$ day dispersed in $0.5 \% \mathrm{CMC}-\mathrm{Na}$ ) orally for 9 consecutive days and a single i.p. injection of CDPP ( $7 \mathrm{mg} / \mathrm{kg}$ dissolved in $0.9 \%$ normal saline) on the $7^{\text {th }}$ day. Rats were weighed regularly during the experiment. $24 \mathrm{~h}$ after CDPP injection, all rats were placed individually in metabolic cages for urine collection. At the end of the experiment (i.e., on the $10^{\text {th }}$ day), rats were anesthetized with ether and sacrificed by cervical decapitation. Kidneys were isolated and stored at $-80^{\circ} \mathrm{C}$ for gene expression analysis by quantitative reverse transcription-polymerase chain reaction (qRTPCR) and electrophoresis.

\section{Data collection and analysis}

Kidney tissue was homogenized with ice-cold saline $0.9 \%$ sodium chloride) using a rotor-stator homogenizer. The mixture was centrifuged for $10 \mathrm{~min}$ at $3000 \times \mathrm{g}$ at $4^{\circ} \mathrm{C}$. The supernatant was then collected, and RNA was isolated using the Tripure Isolation Reagent. Next, cDNA was synthesized using a Transcriptor First Strand cDNA Synthesis Kit (Roche) before two-step qRT-PCR was performed. The purity and concentration of the cDNA in the samples was assessed using a Nanodrop 2000 spectrophotometer. qRT-PCR for CTR1, OCT2, as well as beta-actin as a reference gene was then carried out. The relative expression of CTR1 and OCT2 was calculated using the Livak method by comparing the quantitation cycle values of the treated group with those of the control group. Analysis of the data was carried out using the Statistical Package for the Social Sciences software, version 20. After qRT-PCR, visualization of gene expression was performed by electrophoresis (Bio-Rad). Gels were $2 \%$ agarose immersed in $2 \%$ tris-acetate-ethylenediaminetetraacetic acid buffer. Samples were mixed with SYBR Green loading dye and electrophoresed for $10 \mathrm{~min}$ at $220 \mathrm{~V}$.

\section{RESULTS}

The results of qRT-PCR for CTR1 indicated no association between the administration of CMN and $\mathrm{NC}$ and respective gene expression as shown in Fig. 1. In the analysis, the median was used instead of the average due to the abnormal spread of the data.

The median of OCT2 qRT-PCR results showed an increased expression in rats treated with $\mathrm{CDPP}+100 \mathrm{mg} \mathrm{NC}$ compared with the other groups, although this finding was not significant (Fig. 2).

Statistical analysis showed no statistically significant result for either CTR1 or OCT2 ( $>0.05$ ). Electrophoresis of the CTR1 qRT-PCR product was inconclusive due to only a very slight difference between the expressions (Fig. 3).

Electrophoresis of the OCT2 qRT-PCR product showed an increased expression in the CDPP+100 mg NC group (Fig. 4, the two rightmost wells).

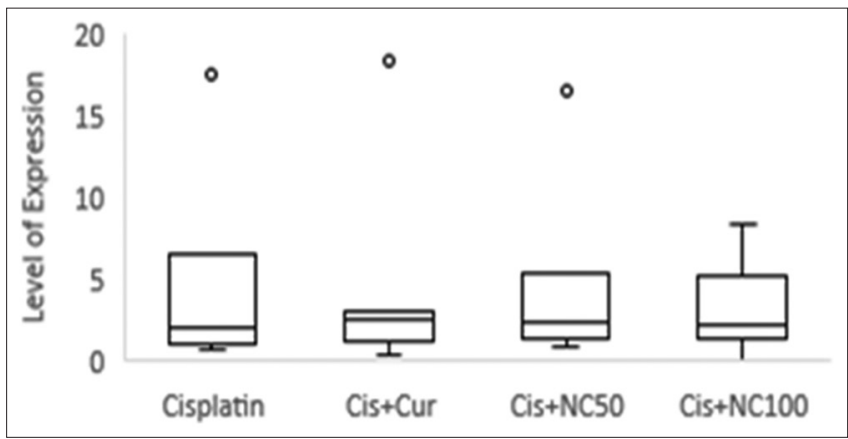

Fig. 1: Expression level of copper transporter 1

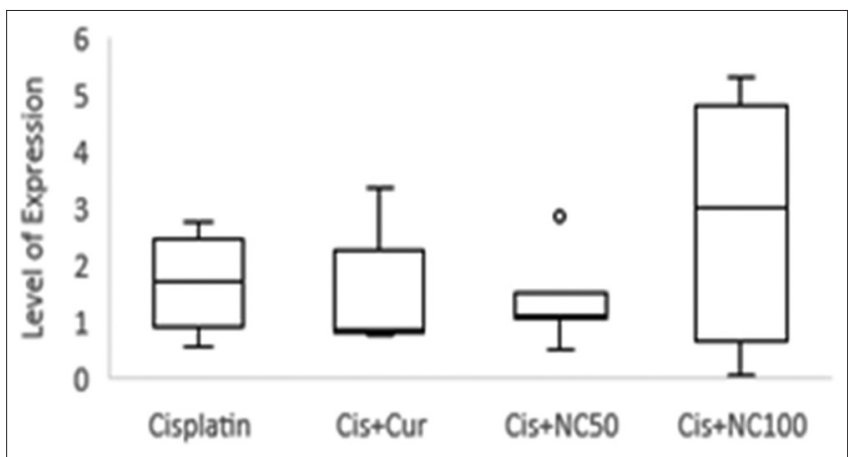

Fig. 2: Expression level of organic cation transporter 2

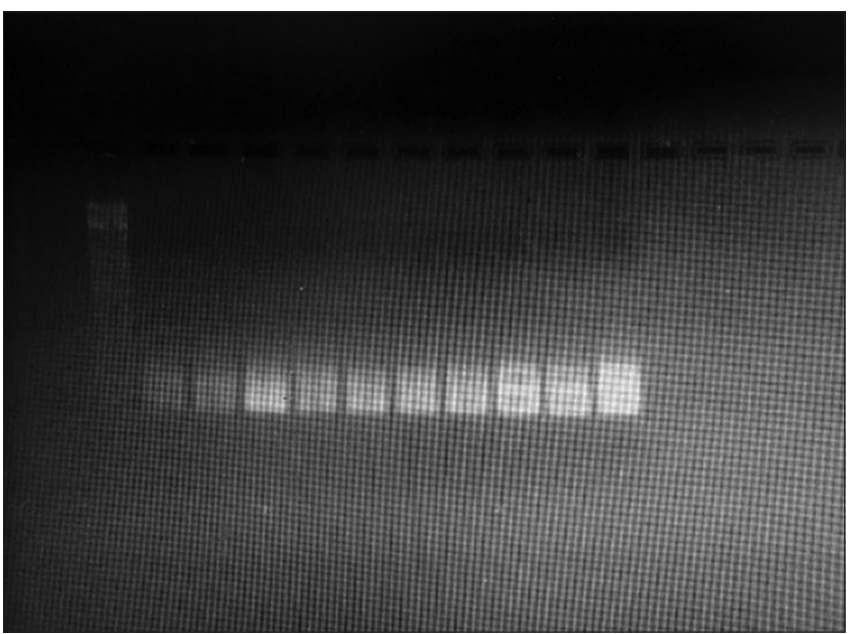

Fig. 3: Electrophoresis of copper transporter 1 


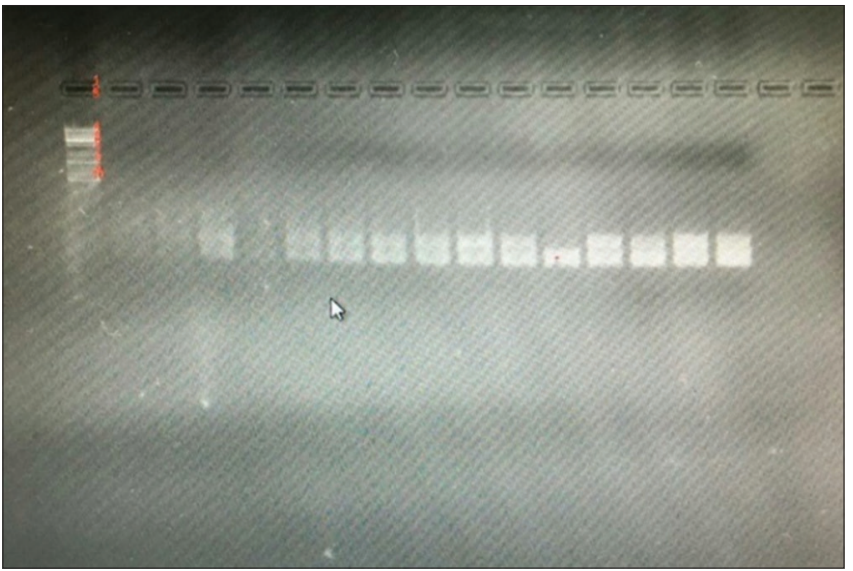

Fig. 4: Electrophoresis of organic cation transporter 2

\section{DISCUSSION}

An important process mediating the cellular accumulation of CDPP inside renal tubular cells is transporter-mediated uptake [6]. Two identified membrane transporters involved in the active accumulation of CDPP into renal tubular cells are CTR1 and OCT2 [19]. However, no study has yet elucidated the effects of CDPP toward CTR1 gene expression or the effect of CMN toward CTR1 gene expression in CDPPinduced nephrotoxicity. As for OCT2, several studies have elucidated that OCT2 expression is suppressed on CDPP treatment, which is presumed to be a natural renoprotective mechanism of the kidney to prevent further toxicity [20]. Therefore, CTR1 and OCT2 expression levels were used in this study to determine whether the renoprotective mechanism of CMN involves CTR1 and whether NC has better renoprotective effects compared with CMN.

Collectively, our research suggested no association between the administration of CMN or NC with CTR1 expression level. Thus, the renoprotective mechanism of CMN does not appear to involve CTR1. However, in accordance with previous studies, OCT2 gene expression was increased in the CDPP $+100 \mathrm{mg} / \mathrm{kg} /$ day NC group. Although the expression was higher than normal levels, this indicates a better renoprotective effect of $\mathrm{NC}$ compared with CMN. These results are expected as the molecular size of $\mathrm{NC}$ would make it more readily dispersed in aqueous solutions, with subsequent better physicalchemical properties compared with CMN. As for the overexpression, this may be caused by another regulatory mechanism from the CMN itself.

\section{CONCLUSION}

The administration of $100 \mathrm{mg} / \mathrm{kg} /$ day NC increased OCT2 expression in rats treated with CDPP; however, this increase was higher compared with normal expression levels. In contrast, CTR1 expression was not associated with the administration of CMN or NC; thus, it does not appear to be involved in the renoprotective mechanism of CMN.

\section{CONFLICTS OF INTEREST}

All authors declare that they have no conflicts of interest.

\section{REFERENCES}

1. Dasari S, Tchounwou PB. Cisplatin in cancer therapy: Molecular mechanisms of action. Eur J Pharm 2014;740:364-78.

2. Sushma M, Prasad KV, Jhansi LB, Vijay R, Uma MR. Prophylactic and curative effect of ethanolic extract of Bassia malabarica bark against cisplatin induced nephrotoxicity. Asian J Pharm Clin Res 2014;7:143-6.

3. Sreedevi A. Alleviation of cisplatin induced nephrotoxicity in albino rats by roots Catunaregam uliginosa. Asian J Pharm Clin Res 2016;9:147-51.

4. Pabla N, Dong Z. Cisplatin nephrotoxicity: Mechanisms and renoprotective strategies. Kidney Int 2008;73:994-1007.

5. Arany I, Safirstein RL. Cisplatin nephrotoxicity. Semin Nephrol 2003;23:460-4.

6. Burger H, Loos WJ, Eechoute K, Verweij J, Mathijssen RH, Wiemer EA, et al. Drug transporters of platinum-based anticancer agents and their clinical significance. Drug Resist Updat 2011;14:22-34.

7. Pabla N, Murphy RF, Liu K, Dong Z. The copper transporter Ctr1 contributes to cisplatin uptake by renal tubular cells during cisplatin nephrotoxicity. J Physiol Renal Physiol 2008;296:F505-11.

8. Ciarimboli G, Ludwig T, Lang D, Pavenstädt $H$, Koepsell H, Piechota HJ, et al. Cisplatin nephrotoxicity is critically mediated via the human organic cation transporter 2. Am J Pathol 2005;167:1477-84.

9. Rezaee R, Momtazi AA, Monemi A, Sahebkar A. Curcumin: A potentially powerful tool to reverse cisplatin-induced toxicity. Pharm Res 2017;117:218-27.

10. Steffi PF, Srinivasan M. Curcumin, a potent anticarcinogenic polyphenol - A review. Asian J Pharm Clin Res 2014;7 Suppl.2:10-8.

11. Shankar TN, Shantha NV, Ramesh HP, Murthy IA, Murthy VS. Toxicity studies on turmeric (Curcuma longa): Acute toxicity studies in rats, guineapigs and monkeys. Indian J Exp Biol 1980;18:73-5.

12. Qureshi S, Shah AH, Ageel AM. Toxicity studies on Alpinia galanga and Curcuma longa. Planta Med 1992;58:124-7.

13. Lao CD, Demierre MF, Sondak VK. Targeting events in melanoma carcinogenesis for the prevention of melanoma. Expert Rev Anticancer Ther 2006;6:1559-68.

14. Lao CD, Ruffin MT, Normolle D, Heath DD, Murray SI, Bailey JM, et al. Dose escalation of a curcuminoid formulation. BMC Complement Altern Med 2006;6:10.

15. Cheng AL, Hsu CH, Lin JK, Hsu MM, Ho YF, Shen TS, et al. Phase I clinical trial of curcumin, a chemopreventive agent, in patients with high-risk or pre-malignant lesions. Anticancer Res 2001;21:2895-900.

16. Shoba G, Joy D, Joseph T, Majeed M, Rajendran R, Srinivas PS, et al. Influence of piperine on the pharmacokinetics of curcumin in animals and human volunteers. Planta Med 1998;64:353-6.

17. Anand P, Kunnumakkara AB, Newman RA, Aggarwal BB. Bioavailability of curcumin: Problems and promises. Mol Pharm 2007;4:807-18.

18. Yallapu MM, Jaggi M, Chauhan SC. Curcumin nanoformulations: A future nanomedicine for cancer. Drug Discov Today 2012;17:71-80.

19. Miller RP, Tadagavadi RK, Ramesh G, Reeves WB. Mechanisms of cisplatin nephrotoxicity. Toxins (Basel) 2010;2:2490-518.

20. Aleksunes LM, Augustine LM, Scheffer GL, Cherrington NJ, Manautou JE. Renal xenobiotic transporters are differentially expressed in mice following cisplatin treatment. Toxicology 2008;250:82-8. 